\title{
Potential of Nanoparticles Chitosan for Delivery pcDNA3.1-tat
}

\author{
Lalu Unsunnidhal ${ }^{1,3}$, Raden Wasito ${ }^{2}$, Erif Maha Nugraha Setyawan ${ }^{1}$, Asmarani Kusumawati ${ }^{*}$ \\ ${ }^{1}$ Department of Reproduction and Obstetrics, Faculty of Veterinary Medicine, University Gadjah Mada, Yogyakarta, 55281,Indonesia \\ ${ }^{2}$ Department of Pathology, Faculty of Veterinary Medicine, University Gadjah Mada, Yogyakarta, 55281, Indonesia \\ ${ }^{3}$ Biomedical Field, Nursing Study Program, STIKES Yarsi Mataram, West Nusa Tenggara, 83361, Indonesia
}

\begin{abstract}
The development of Jembrana disease vaccine is importance to prevent the loss of Bali cattle industry in Indonesia. This study aims to prepare a Jembrana DNA vaccine. The data Tat protein sequences gained from NCBI and the consensus process has been finished by the MultAlign program, and then Cloning of the pcDNA3.1-tat has been successfully performed on E. coli DH5 $\alpha$ and confirmed by PCR, restriction analysis and sequencing. The propagated plasmids were prepared as DNA-chitosan complex and physiochemical characterized using Particle Size Analyzer. Complex with a 1:2 (wt/wt) ratio of DNA and chitosan have a mean diameter of $268.5 \mathrm{~nm}$ and zeta potential $+25.1 \mathrm{mV}$ and the value of Cytotoxicity Assay $80-90 \%$ as compared to the untreated cells that used as negative control, so it can be concluded that nanoparticles chitosan has good potential as a carrier agent for pcDNA3.1-tat. Keywords: A consensus sequences, Chitosan nanoparticles, JDV Tat protein, Jembrana disease virus, Delivery System
\end{abstract}

\section{Introduction}

To meet the needs of the Indonesian people for the source of meat protein, an effort is made to increase thebeef cattle population. One of the beef cattle is Bali Cattle (Bos javanicus), Bali Cattle (Bos javanicus) as a local meat source is expected to be the main source of beef replacing imported cattle. However, the effort to increase the population of Bali cattle is hampered by diseases caused by viruses, one of which is Jembrana disease, the only infectious disease attacking Bali Cattle. This disease is caused by viruses from the genus Lentiviridae [1], [2] known as the Jembrana Disease Virus (JDV) which has caused high mortality in Bali cattle in Indonesia.

Treatment of using antibiotics against diseases caused by viruses feels less effective. Therefore, other alternative prevention strategies are needed, such as developing more competent vaccines. Generally, vaccines are produced from attenuated disease agents or antigens isolated from a disease agent. However, the vaccine has several drawbacks, such as limited supply of materials and complicated isolation techniques that take time. This encourages experts to develop vaccines through recombinant DNA techniques. The vaccine is made by entering DNA or genes that encode immunogenic proteins into eukaryotic expression vectors.

Tat protein is one of the accessory proteins that strongly activate the viral long terminal repeat (LTR) and essentially induce the transcription of viral genes for replication [3]. This protein can interact with the transactivation response (TAR) element and recruit the positive transcription elongation factor $\mathrm{b}$ (P$\mathrm{TEFb}$ ), which relieves the transcriptional block [4][6]. JDV encodes a Tat protein that closely related to the BIV Tat, which can strongly activate not only the JDV LTR but also the LTRs of other lentiviruses, including HIV and BIV [7], [8]. Tat can specifically recognize the heterologous TAR RNAs using very different mechanisms [9]. Moreover, JDV Tat can functionally be substituted for the HIV Tat when the JDV tat gene is introduced into the HIV genome [8], suggesting similar mechanisms may be shared between JDV and HIV Tat (HTat) proteins.

DNA vaccines require delivery systems to work

optimally. DNA vaccines have the disadvantage of low effectiveness in triggering the immune system in organisms due to limitations in the delivery system [10]. On the other hand, the delivery system using nanoparticle chitosan is widely used as a delivery system in DNA in gene therapy; This occurs because of the positive charge of nanoparticle chitosan which can be DNA condensation reagents [11], [12]. In addition, chitosan nanoparticles are also known to have strong electrostatic interactions with negative DNA charges [11], [12]. This causes chitosan nanoparticles to be good candidates for DNA delivery systems [11], [12]. Based on the above description, this study aims to evaluate the in vitro potential of nanoparticle chitosan as a carrier system for recombinant DNA (tat) as a model carrier system for the DNA vaccine.

\section{Material and methods}

\footnotetext{
Corresponding author: uma_vet@ugm.ac.id
} 


\subsection{Construction of Tat1 protein expression cassettes}

In this study, a synthetic DNA vaccine was designed based on the consensus sequence of the Tat1 proteins. The part dedicated to JDV was based on consensus sequences specific for Tat1 proteins generated from global alignments of JDV sequences in databanks, despite the fact that only a few numbers available. The amino acid sequence alignment was performed using MultAlin online software from

http://multalin.toulouse.inra.fr/multalin/ [13]. The consensus sequence was optimized using codon optimization with target host Bos taurus using the services of Gene Universal Inc. Several motif sequences that potentially produce lower expression such as Chi site (GCTGGTGG), ter site core (GTTGTAAC), polyA sites (AATAAA or ATTAAA), consensus eukaryotic promoter core (TATA), immunosuppressive telomeric motif (TTAGGG), DNA uptake sequences (GCCGTCTGAA, AAGTGCGGT or ACAAGCGGTC), consensus splice donor (AGGT), consensus splice acceptor (CAGG), polyA binding proteins consensus (AAAAA), polyT binding proteins consensus (TTTTT) and DnaA binding site (TTATCCACA) were substituted using codon optimization process [14]. The expression cassette was constructed by adding a start codon and a double-codon stop. The gene was synthesized using the Custom Gen Synthesis service by Gene Universal Inc. and cloned to one of the available standard vectors, pcDNA3.1 $(+)$ to produce pcDNA3.1(+)-JDV tat gene.

\subsection{Plasmid preparation and confirmation}

The cloned plasmid from Gene Universal Inc. would be transformed into the host bacteria (E. coli DH5 $\alpha$ ) for the production of DNA vaccine on a larger scale. The preparation of the chemically competent bacterial cells based on the calcium chloride method. At first, Escherichia coli DH5 $\alpha$ was propagated in a shaker incubator at $37^{\circ} \mathrm{C}, 150 \mathrm{rpm}$ for 16 hours and subcultured into a new medium with the same conditions until the optimal density value reaches 0.4 . A total of $1.5 \mathrm{ml}$ of bacterial culture was transferred into a $1.5 \mathrm{ml}$ tube (Biologix), incubated on ice for 30 minutes, precipitated using centrifugation $\left(4000 \mathrm{rpm}, 10 \mathrm{~min}, 4^{\circ} \mathrm{C}\right)$. The pellets were resuspended with $1.5 \mathrm{ml}$ of cold sterile $\mathrm{CaCl} 2100 \mathrm{mM}$ (Sigma), incubated on ice for 30 minutes with an occasional shaking, and precipitated using centrifugation again $\left(4000 \mathrm{rpm}, 10 \mathrm{~min}, 4^{\circ} \mathrm{C}\right)$. The pellet was resuspended with $30 \mu \mathrm{l}$ of cold sterile $100 \mathrm{mM}$ $\mathrm{CaCl} 2$ and incubated again on ice for 2 hours.

An amount of 10 ng DNA plasmid pcDNA3.1(+)Jtat was added to the competent cell and incubated on ice for 30 minutes. The cells were subjected to heating at $42^{\circ} \mathrm{C}$ for 45 seconds. The cells were incubated on ice quickly for 2 minutes. A total of $0.9 \mathrm{ml}$ of Luria Bertani Broth at $37 \mathrm{oC}$ was added after heat shock treatment and then the cells were incubated at $37 \mathrm{oC}$ for 1.5 hours with shaking. A total of $50 \mu \mathrm{l}$ cell cultures were grown on Luria Bertani agar medium containing $100 \mu \mathrm{g} / \mathrm{ml}$ of Ampicillin (Sigma). In addition, competent cells transformed with water were used as negative controls. Two colonies in Ampicillin selection medium were picked and suspended into the mastermix using sterile white tip (Axigen) $(10 \mu \mathrm{l})$ for first confirmation using PCR. The master mix contained $5 \mu 1$ GoTaq Master Mix 2X (Promega), $3.4 \mu 1$ nuclease-free water (Qiagen), 0.8 $\mu \mathrm{l}$ primer forward Tat (5,

TAACTGCTGGCTGTTCTGGA- 3') $10 \mu \mathrm{M}$ (IDT) and $0.8 \mu \mathrm{l}$ Primer reverse Tat (5'TGCCCCTCTTCTTTCTCCTT- 3') $10 \mu \mathrm{M}$ (IDT). These primers were designed based on the consensus sequence using primer3 software from https://primer3plus.com/cgi-bin/dev/primer3plus.cgi to amplify the specific fragment of the tat gene with the product size of $149 \mathrm{bp}$. The PCR was performed under the conditions of pre-denaturation at $950 \mathrm{C}$ for 5 minutes, denaturation at $95 \mathrm{oC}$ for 30 seconds, annealing at $53.5 \mathrm{oC}$ for 30 seconds, elongation $72 \mathrm{oC}$ for 30 seconds, post- elongation at $72 \mathrm{oC}$ for 10 minutes. All of the above processes were conducted for 25 cycles. The PCR products were electrophoresed in 1.5\% agarose gel (Lonza) contained SYBR Safe DNA Gel Stain (Invitrogen) and visualized under the UV illuminator.

The positives clones were picked up again from media selection and cultured on a $10 \mathrm{ml}$ liquid medium containing $100 \mu \mathrm{g} / \mathrm{ml}$ of Ampicillin with shaking 150 $\mathrm{rpm}$ at $37^{\circ} \mathrm{C}$ for 16 hours. Subsequently, the culture was inoculated into a new $140 \mathrm{ml}$ liquid medium containing $100 \mu \mathrm{g} / \mathrm{ml} \mathrm{Ampicillin} \mathrm{and} \mathrm{incubated} \mathrm{with} \mathrm{the} \mathrm{same}$ conditions before. The plasmid isolation from the bacterial cells was performed by using Plasmid DNA Extraction Maxi Kit (Favorgen Biotech Corp). Furthermore, the concentration of the obtained plasmid was measured using Nanodrop (Maestro Gen). The plasmid was visualized in $1.5 \%$ agarose gel (Lonza) with SYBR Safe DNA Gel Stain (Invitrogen). Before loading to the gel, the plasmid was mixed with a $5 \mathrm{X}$ dye DNA Pilot Gel (Qiagen), a loading buffer. The further confirmation was performed by restriction analysis using BamHI and EcoRI. Amount of $1 \mu \mathrm{g}$ plasmid was mixed with $1 \mu \mathrm{L}$ BamHI (10 U/ $\mu 1$, Invitrogen), $1 \mu \mathrm{L}$ enzyme EcoRI (20 U/ $\mu \mathrm{L}$, Invitrogen), $2 \mu \mathrm{L}$ buffer restriction enzyme (Invitrogen) and nuclease-free water (Qiagen) to the final volume of $20 \mu \mathrm{L}$. The mixture was incubated at $37^{\circ} \mathrm{C}$ overnight. The restriction enzymes were inactivated by heating at $85 \mathrm{oC}$ for 20 minutes. The result was electrophoresed in $1 \%$ agarose gel. The expected size of the plasmid backbone is $5400 \mathrm{bp}$, while the expected size of the Jtat fragment is $327 \mathrm{bp}$.

The last confirmation was the sequencing of the inserted gene in the plasmid. The inserted gene was amplified using PCR. The master mix contained $30 \mu \mathrm{l}$ GoTaq Master Mixes 2X (Promega), $4.8 \mu$ l Primer CMV-F (5'-TAATACGACTCACTATAGG-3') $10 \mu \mathrm{M}$ (IDT), $4.8 \quad \mu \mathrm{l}$ Primer BGH-R (5'-

TAGAAGGCACAGTCGAGG-3') $10 \mu \mathrm{M}$ (IDT), $17.4 \mu 1$ nuclease-free water (Qiagen) and $3 \mu \mathrm{l}$ of plasmid as a template. The primer pair used was the Universal primer pair for the sequencing primers on the pcDNA3.1(+) vector. The PCR was conducted under the conditions of predenaturation at $95 \mathrm{oC}$ for 5 minutes, denaturation at $95 \mathrm{oC}$ for 30 seconds, annealing at $51 \mathrm{oC}$ for 30 seconds, elongation $72 \mathrm{oC}$ for 1.5 minutes, and 
post-elongation at $72 \mathrm{oC}$ for 10 minutes. All processes were conducted for 25 cycles. The PCR products were sent for sequencing service (First Base, Singapore) and then sequenced data were analyzed using the ClustalW online program at www.genome.jp/tools-bin/clustalw.

\subsection{Preparation of chitosan-DNA plasmid complex}

The chitosan with medium molecular weight (Sigma, no. product: 448877) was dissolved in $1 \%$ acetic acid solution (Sigma) and the $\mathrm{pH}$ of the solution was adjusted to 5.0 using $1 \mathrm{M} \mathrm{NaOH}$ (Sigma). This polymer solution with a final concentration of $0.02 \%$ was sterilized by using filter $0.2 \mu \mathrm{m}$. Different formulations were produced in this study with various mass ratios. All ratios used $1 \mu \mathrm{g}$ recombinant DNA and different amount of chitosan to make different formulation 1:0.5; 1:1; 1:2; $1: 3 ; 1: 4$ (wt./wt.). The chitosan-DNA complex was prepared by using coarsevation complex method [11], [12]. The chitosan and DNA plasmid solutions heated separately at $50^{\circ} \mathrm{C}$ for $10 \mathrm{~min}$. Then, the two solutions were mixed at $2500 \mathrm{rpm}$ for 30 seconds. The formation of the complex between the positive charge of chitosan and negative plasmid DNA could be observed by agarose gel electrophoresis. The chitosan-DNA plasmid complexes were electrophoresed in $0.8 \%$ agarose gel with SYBR Safe DNA Gel Stain (Invitrogen). The samples of chitosan-DNA complex were compared with free DNA samples and chitosan only.

\subsection{Characterization: particle size, potential zeta, and cytotoxicity assay}

The measurement of particle size was calculated by SZ100 (HORIBA Scientific) at $24.9 \mathrm{oC}$ and scattering angle $90 \mathrm{o}$, while the measurement of zeta potential was calculated by SZ-100 (HORIBA Scientific) at 24.8oC and electrode voltage 3.3 Volt.

The effect of the transfecting agents on the cells after transfection were investigated using the MTT assay. The HeLa cells were seeded in a 96 well plate with the initial density of $5 \times 103$ cells per well in $200 \mu \mathrm{L}$ supplemented DMEM medium. After $24 \mathrm{~h}$, the cells were treated with plasmid, chitosan, and chitosan-DNA complex for $4 \mathrm{~h}$. The medium was replaced with fresh medium and incubated for $24 \mathrm{~h}$. Then, the medium was replaced by $100 \mu \mathrm{L}$ of MTT stock solution and incubated again for $3 \mathrm{~h}$ at $37^{\circ} \mathrm{C}$ in a $\mathrm{CO} 2$ incubator. The stopper reagent contained SDS 10\% was added into the well. The untreated HeLa cells were used as a negative control. The absorbance of the dye in the solution was measured at the wavelength of $500 \mathrm{~nm}$ with ELISA plate reader.

\section{Results}

\subsection{Construction of Tat1 protein expression cassettes}

In this study, a DNA vaccine against Jembrana Disease Virus was constructed based on the consensus sequence from amino acid sequences of Tat1 protein. Four amino acid sequences from NCBI were aligned using the MultAlign program to generate the consensus sequences (Figure 1A). Those sequences chosen from database were the JDV Pulukan/2000 (ABV80250); JDV (Q82854); JDV Tabanan/87 (AAA64392); and JDV Kalimantan/2000 (ABV80251). The tat gene was optimized in the host bos taurus as a model to produce the synthetic gene sequences (Figure 1B). The expression cassettes were constructed by adding BamHI and EcoRI restriction sites for cloning sites, ATG codon as a start codon, TAATAA codons as a double-codon stop. The gene was synthesized using the Custom Gen Synthesis service by Gene Universal Inc. and cloned to one of the available standard vectors, pcDNA3.1 $(+)$ to form the recombinant plasmid pcDNA3.1(+)-JDV tat gene.

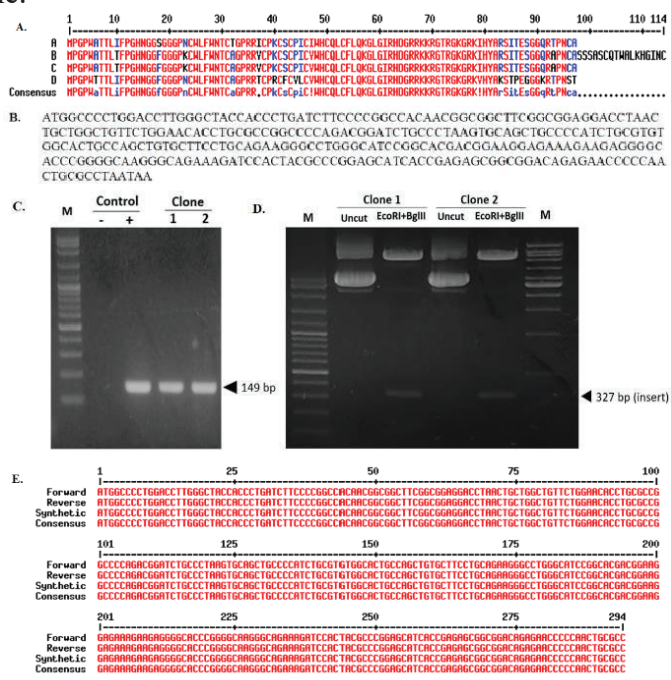

Figure 1. Construction of Tat1 protein expression cassettes and preparation of DNA plasmid. Alignment

of Tat1 amino acids from four Tat1 sequences using the MultAlign program (A). Either the most frequent or and arbitrary $(*)$ chosen amino acid was introduced. Tat1 sequence: A. JDV Pulukan/2000 (ABV80250); B. JDV (Q82854); C. JDV Tabanan/87 (AAA64392); D. JDV Kalimantan/2000 (ABV80251). The optimized nucleotide sequence for Tat protein produced by codon optimization (B). The confirmation of selected clone by using colony-PCR (C). Untransformed bacteria (control $-)$, plasmid with tat gene (control + ) and two selected clone from the media (clone 1 and 2). The confirmation of insert gene using restriction analysis with EcoRI and BamHI (D), undigested plasmid (Uncut) and digested plasmid (cut). Confirmation with Sanger sequencing (Forward and Reverses) used CMV-F and BGH-R primers (E).

\subsection{Preparation of DNA plasmid}

The synthetic gene was chemically produced and cloned into pcDNA3.1 $(+)$ vector with restriction sites of EcoRI and BamHI to build pcDNA3.1-JDV tat gene. The transformation into E. coli DH5 $\alpha$ as vector cloning was performed for larger scale production of DNA plasmid. This plasmid has a selectable marker for ampicillin 
resistance. Two chosen ampicillin-resistant bacteria in the selection media were confirmed by colony-PCR with primer Tat-For and Tat-Rev and showed a specific band (149 bp) ( Figure 1C). The plasmid extracted from those positive clones were also checked with restriction analysis (Figure 1D) to give two distinct bands that corresponding with the vector fragment (about $5400 \mathrm{bp}$ ) and JDV tat gene fragment (327 bp). One of those clones was chosen to be confirmed with Sanger sequencing using CMV-F and BGH-R primers. The result of the sequencing and the initially designed transgene were aligned using online software and the results showed that the transformation process into the cloning vector did not induce any mutations in the nucleotide composition of JDV tat gene (Figure 1E).

\subsection{Chitosan-DNA Complex Preparation}

The formation of chitosan-DNA complex was first observed with a gel retardation assay on agarose gel electrophoresis (Figure 2). Several different mass ratios of DNA and chitosan were used: 1:0.5, 1:1.0, 1:2.0, $1: 3.0$, and 1:4.0 (wt./wt.), and all complexes were formed in the same total solution volume. The chitosan solution as a negative control cannot bind to the DNA dye, so it did not produce luminescence in the gel. The free plasmid DNA migrates into three DNA bands showing three different plasmid conformations. As the mass of chitosan increases in the formulation, the free DNA plasmid that is able to migrate also decreases. The luminescence of free plasmid DNA could still be detected in nanoparticles with a ratio of 1:0.5 and 1:1.0 but was not detected in the higher chitosan ratio solutions. The more chitosan that is added in the formulation, the more plasmid DNA is trapped to form a chitosan-DNA complex. From the visualization in agarose gel, the 1:2 mass ratio is the minimum ratio of chitosan to capture the entire amount of DNA plasmid. For that reason, this complex was further analyzed with other parameters.

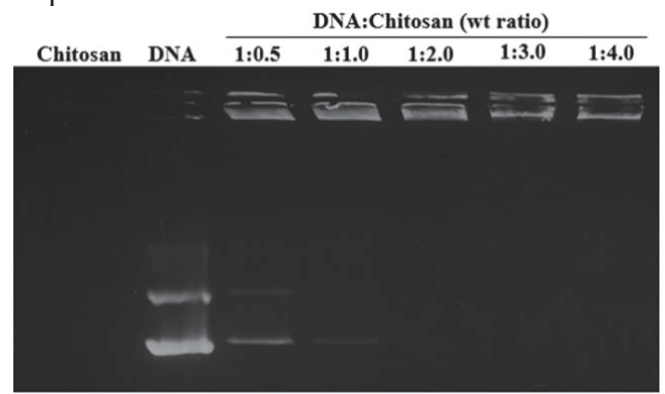

Figure 2. Agarose gel retardation assay of chitosanDNA plasmid complexes. The complexes contained the different amount of chitosan (wt. ratio). The same amount of unbound plasmid (DNA) and chitosan solution (Chitosan) were used as negative control.

\subsection{Characterization of chitosan-DNA plasmid}

The physicochemical characterizations were performed to investigate the further properties of the chitosan-DNA complex. These properties were measured by using dynamic light scattering (DLS) method by examining the random changes in the scattering light intensity detected in the solution. The average size and surface charge of the complex prepared from unmodified chitosan are shown in Figure 3. The mean particle size for chitosan-DNA complex was 268.5 $\mathrm{nm}$, while the zeta potential of this complex was found to be $25.1 \mathrm{mV}$.

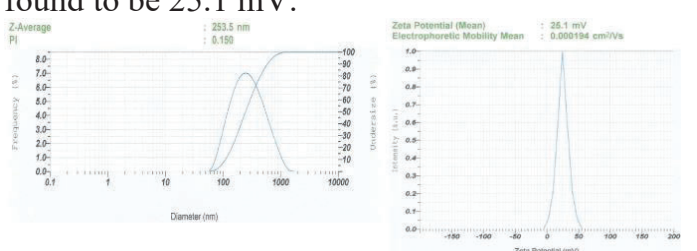

Figure 3. Characterization analyses of chitosan-DNA plasmid complex: particle size distribution (A) and zetapotential value measurement (B) using particle sizeanalyser.

\subsection{Cytotoxicity assay of chitosan- DNAplasmid}

The cytotoxicity assay in this study was utilized to evaluate the impact of the chitosan-DNA plasmid complex on cellular viability. MTT assay will measure the decrease in mitochondrial activity in the cells in the presence of our complex at the defined contact time. This assay for the chitosan-DNA complex formed at $\mathrm{pH} 5.0$ showed that in the exposure time as long as 4 hours, this chitosan complex was not harmful to the cells. The viability of the HeLa cells was about $80-90 \%$ as compared to the untreated cells that used as negative control.

\section{Discussion}

Plasmid pcDNA3.1(+) has been used previously as a DNA vaccine vector against various infectious disease such as Brucella abortus [15], grass carp reovirus [16] or human immunodeficiency virus-1 [17]. This study will use the pcDNA3.1(+) vector to encode a synthetic gene constructed from a consensus sequence of one gene from JDV. This strategy that designs a novel vaccine based on the consensus of amino acid sequences has been previously implemented to develop a vaccine against rabies virus [18], avian influenza [19] or hepatitis B [20]. Moreover, this study will also test the success of this vaccine delivery on in vitro level by formulating it in the form of chitosan complex. Chitosan is broadly employed in the pharmaceutical sector as a carrier agent that is able to release molecules in a controlled manners, such as DNA, vaccines, peptides, or antibiotics. This kind of delivery system has been employed in different vaccine candidate cases, such as intranasal chitosan-DNA vaccine for influenza virus [21], the oral chitosan-DNA vaccine against nodavirus [22] or vaccine for Trueperella pyogenes infection [23]. This study will evaluate chitosan complex as DNA vaccine delivery system at in vitro level to deliver the DNA plasmid encoding a gene of interest from JDV. In this case, the HeLa cell line would be used as a model to test the delivery of DNA vaccine across the eukaryotic membrane cells. 
In this study we designed synthetic Tat-1 protein sequence using consensus sequence. Despite the facts that data availability for HIV Tat-1 antigenicity in PubMed was so high, there was no single data for JDV Tat-1 antigenicity. We also realized that Tat-1 protein was not strong DNA vaccine candidate, compared to Env and Gag protein [24]. We designed Tat-1 consensus protein, so in the near future we could get the data about its antigenicity. Consensus approach was based on the hypothesis that at a given position, the respective consensus amino acid more stable than non- conserved amino acids [25]. The consensus design approach has been give high impact in the stabilities of functional and non-functional proteins [26]. Again, we met the edge because too little data about its variation. In consensus design we aligned all sequences are, and we used the most frequently observed amino acid using software as listed before.

The second stage for the designing of this DNA vaccine is the construction of a codon-optimized nucleotide sequence which encodes Tat consensus antigen. The codon optimization of this gene sequence was recommended to increase the expression of Lentivirus gene in a eukaryotic host [27]. Additionally, some motif sequences were suggested to be excluded to avoid the lower plasmid production in host cloning or lower translation of target protein in the host expression [14]. Prior to the preparation of plasmid in a higher yield, the transformed plasmid in the host cloning had to be confirmed to make sure there is no mutation take place in the host cloning. The confirmations such as PCR, restriction analysis and sequencing were performed to ensure the expression cassette could produce the desired amino acid sequence.

In this study, the mean diameter of chitosan-DNA complex $253.5 \mathrm{~nm}$ with a polydispersion index value of

0.150 (Figure 3). This size falls in the range around $100-250 \mathrm{~nm}$ so it showed that this complex has a normal size for a complex that produced by using coarsevation complex method [28]. The particle size is thought to be the main factor that affects particle uptake and gene delivery into the cells [29]. A particle with a size higher than $100 \mathrm{~nm}$ is proven to enter the cells through endocytosis or pinocytosis [30]. Furthermore, the pI values of the complex that fall in the range between 0.01 to 0.7 showed that this particle behaved as a monodispersed system, while the higher value of $\mathrm{pI}$ than

0.7 would indicate larger particle size distribution in the solution [31]. Another physiochemical character observed was zeta potential that shows the charged of the complex. The complex produced in this study has a zeta potential value of $+25.1 \mathrm{mV}$. A positively charged complex was likely to be easily attached to the cell membrane that has a negative charge and be internalized into the cells through endocytosis [29].

Another important assay that had to be performed before transfection study is the cytotoxicity assay. In this study, the MTT assay was conducted to evaluate the effect of the chitosan complex to the viability of the cells during exposure time with the cells. The positive charge of the polycationic charge like chitosan complex can interact strongly with plasma membrane protein through an electrostatic bond, destabilize it and ultimately rupture the membrane structure of the cell [29]. Under 4 $\mathrm{h}$ of transfection, chitosan solution and chitosan-DNA complex showed the relative viability with the value higher than $90 \%$. The similar chitosan complexes that result to a relative viability ranging from $80-90 \%$ was still reviewed to have no high toxicity potential [11], [12]. This test indicates that chitosan complex does not exhibit a high toxicity potential for the cell during exposure time for transfection study.

\section{References}

1. G. Kertayadnya, G. E. Wilcox, N. Soeharsono, S. Hartaningsih, R. J. Coelen, R. D. Cook, and J. Brownlie, "Characteristics of a retrovirus associated with Jembrana disease in Bali cattle," J. Gen. Virol., vol. 74, no. 9, pp. 1765-1773, 1993, doi: https://doi.org/10.1099/0022- 1317-74-91765.

2. B. J. Chadwick, R. J. Coelen, G. E. Wilcox, L. M. Sammels, and G. Kertayadnya, "Nucleotide Sequence Analysis of Jembrana Disease Virus : A Bovine Lentivirus Associated with An Acute Disease Syndrome," J Gen Virol., vol. 76, pp. 1637-1650, 1995, doi: DOI:10.10990022-131776-7-1637.

3. H. Chen, G. Wilcox, E. Kertayadnya, G, D, and C. Wood, "Characterization of The Jembrana Disease Virus tat Gene and the cis- and Trans- Regulatory Elements in Its Long Terminal Repeats," J. Virol., vol. 73, no. 1, pp. 658-666, 1999.

4. H. S. Y. Mancebo et al., "P-TEFb kinase is required for HIV Tat transcriptional activation in vivo and in vitro," Genes Dev., vol. 11, pp. 26332644, 1997.

5. N. F. Marshall, J. Peng, Z. Xie, D. H. Price, and J. B. Chem, "Control of RNA Polymerase II Elongation Potential by a Novel Carboxylterminal Domain Kinase * tiation activity of positive transcription elongation fac-," J. Biol. Chem., vol. 271, no. 43, pp. 27176-27183, 1996.

6. Y. Zhu et al., "Transcription elongation factor P$\mathrm{TEFb}$ is required for HIV-1 Tat transactivation in vitro," Genes Dev., vol. 11, pp. 2622-2632, 1997.

7. C. Cheng-Mayer, T. Shioda, and A. Levy, J, "Host Range, Replicative, and Cytopathic Properties of Human Immunodeficiency Virus Type 1 Are Determined by Very Few Amino Acid Changes in tat and gpl20," J. Virol., vol. 65, no. 12, pp. 69316941, 1991

8. H. Chen, J. U. N. He, S. Fong, and G. Wilcox, "Jembrana Disease Virus Tat Can Regulate Human Immunodeficiency Virus ( HIV ) Long Terminal Repeat-Directed Gene Expression and Can Substitute for HIV Tat in Viral Replication," J. Virol., vol. 74, no. 6, pp. 2703-2713, 2000, doi: 10.4161hv.7.12.17983.

9. C. A. Smith, V. Calabro, A. D. Frankel, and S. Francisco, "An RNA-Binding Chameleon," Mol. 
Cell, vol. 6, pp. 1067-1076, 2000, doi: 10.1016S1097-2765(00)00105-2.

10. G. Wang, L. Pan, and Y. Zhang, "Approaches to Improved Targeting of DNA Vaccines," Hum Vaccines., vol. 7, pp. 1271-1281, 2011, doi: DOI:10.4161hv.7.12.17983.

11. L. Unsunnidhal, J. Ishak, and A. Kusumawati, "Expression of gag-CA Gene of Jembrana Disease Virus with Cationic Liposomes and Chitosan Nanoparticle Delivery Systems as DNA Vaccine Candidates," Trop. Life Sci. Res., vol. 30, no. 3, pp. 15-36, 2019, doi: https://doi.org/10.21315/tlsr2019.30.3.2.

12. J. Ishak, L. Unsunnidhal, R. Martien, and A. Kusumawati, "In vitro evaluation of chitosanDNA plasmid complex encoding Jembrana disease virus Env-TM protein as a vaccine candidate," J. Vet. Res., vol. 63, no. 1, pp. 7-16, 2019, doi: https://doi.org/10.2478/jvetres-2019-0018.

13. F. Corpet, "Multiple Sequence Alignment with Hierarchical Clustering," Nucleic Acids Res., vol. 16, no. 22, pp. 10881-10890, 1988.

14. J. Williams, "Vector Design for Improved DNA Vaccine Efficacy, Safety and Production," Vaccines, vol. 1, no. 3, pp. 225-249, 2013, doi: 10.3390/vaccines 1030225 .

15. D. Luo et al., "Protective Immunity Elicited by A Divalent DNA Vaccine Encoding Both The L7/L12 and Omp16 Genes of Brucella abortus in BALB/c Mice," Infect Immun, vol. 74, no. 5, pp. 2734-2741, 2006, doi: DOI:10.1128/IAI.74.5.2734-2741.2006.

16. Y. Gao, C. Pei, X. Sun, C. Zhang, L. Li, and X. Kong, "Plasmid pcDNA3.1-s11 Constructed Based on The S11 Segment of Grass Carp Reovirus as DNA Vaccine Provides Immune Protection," Vaccine, vol. 36, no. 25, pp. 36133621, 2018, doi: 10.1016/J.VACCINE.2018.05.043.

17. M. T. Shata, M. S. Reitz Jr., A. L. DeVico, G. K. Lewis, and D. M. Hone, "Mucosal and systemic HIV-1 Env-specific CD8+ T-cells Develop after Intragastric Vaccination with A Salmonella Env DNA Vaccine Vector," Vaccine, vol. 20, no. 3-4, pp. 623-629, 2001, doi: 10.1016/S0264410X(01)00330-9.

18. S. Starodubova, E, V. Kuzmenko, Y, A. Latanova, A, V. Preobrazhenskaya, O, and L. Karpov, V, "Creation of DNA vaccine vector based on codonoptimized gene of rabies virus glycoprotein (G protein) with consensus amino acid sequence," Mol. Biol., vol. 50, no. 2, pp. 328-331, Mar. 2016, doi: $10.1134 / \mathrm{S} 0026893316020242$.

19. D. J. Laddy, J. Yan, N. Corbitt, G. P. Kobinger, and D. B. Weiner, "Immunogenicity of novel consensus-based DNA vaccines against avian influenza," Vaccine, vol. 25, no. 16, pp. 29842989, Apr. 2007, doi: 10.1016/j.vaccine.2007.01.063.
20. R. Jannah and L. Unsunnidhal, "KONSTRUKSI DAN KLONING PLASMID PCDNA3 . $1(+)$ DENGAN SUBGENOTIP B3 HEPATITIS B CORE ANTIGEN ( HBcAg) SEBAGAI KANDIDAT VAKSIN DNA HEPATITIS B," J. Penelit. dan Kaji. Ilm. Kesehat., vol. 5, no. 2, pp. 125-131, 2019.

21. C. Sawaengsak et al., "Intranasal Chitosan- DNA Vaccines that Protect Across Influenza Virus Subtypes," Int J App Pharm, vol. 473, no. 1-2, pp. 113-125, 2014, doi: 10.1016/j.ijpharm.2014.07.005.

22. Y. Valero et al., "An Oral Chitosan DNA Vaccine Against Nodavirus Improves Transcription of Cell-Mediated Cytotoxicity and Interferon Genes in The European Sea Bass Juveniles Gut and Survival Upon Infection," Dev Comp Immunol., vol. 65, pp. 64-72, 2016, doi: 10.1016/j.dci.2016.06.021.

23. T. Huang et al., "Chitosan - DNA Nanoparticles Enhanced The Immunogenicity of Multivalent DNA Vaccination on Mice agaInst Trueperella pyogenes Infection," J. Nanobiotechnology, vol. 16, no. 8, pp. 1-15, 2018.

24. L. D. Pearson, M. L. Poss, and J. C. Demartini, "Animal Lentivirus Vaccines: Problems and Prospects," Vet Immunol Immunop, vol. 20, pp. 183-212, 1989, doi: 10.1016/01652427(89)90002-0.

25. T. Porebski, B and M. Buckle, A, "Consensus Protein Design," Protein Eng Des Sel, vol. 29, no. 7, pp. 245-251, 2016, doi: 10.1093/protein/gzw015.

26. T. Porebski, B et al., "Structural and Dynamic Properties that Govern The Stability of An Engineered Fibronectin Type III Domain," Protein Eng Des Sel, vol. 28, no. 3, pp. 67-78, 2015, doi: 10.1093/protein/gzv002.

27. J. Haas, C. Park, E, and B. Seed, "Codon usage limitation in the expression of HIV-1 envelope glycoprotein," Curr. Biol., vol. 6, no. 3, pp. 31524, Mar. 1996.

28. A. E. Gregory, R. Titball, and D. Williamson, "Vaccine Delivery using Nanoparticles," Front Cell Infect Mi, vol. 3, p. 13, 2013, doi: 10.3389/fcimb.2013.00013.

29. S. Nimesh, M. M. Thibault, M. Lavertu, and M. D. Buschmann, "Enhanced Gene Delivery Mediated by Low Molecular Weight Chitosan/DNA Complexes: Effect of $\mathrm{pH}$ and Serum," Mol Biotechnol., vol. 46, no. 2, pp. 182196, 2010, doi: 10.1007/s12033-010- 9286-1.

30. J. C. Venter et al., "The sequence of the human genome," Science (80-. )., vol. 291, pp. 13041351, 2001.

31. A. A. Kharia, A. K. Singhai, and R. Verma, "Formulation and Evaluation of Polymeric Nanoparticles of An Antiviral Drug for Gastroretention,” Int. J. Pharm. Sci. Nanotechnol., vol. 4, no. 4, pp. 1557-1562, 2012. 